Impact Factor: 4.845(SJIF) Research Journal Of English (RJOE) Vol-5, Issue-2, 2020

www.rjoe.org.in An International Peer-Reviewed English Journal

ISSN: 2456-2696

Indexed in: International Citation Indexing (ICI), International Scientific Indexing (ISI), Directory of Research Journal Indexing (DRJI) Google Scholar \& Cosmos.

\title{
A JOURNEY TO THE CITY: ANALYSING THE FAMILY TRANSITION IN SELECT MALAYALAM CINEMA
}

\author{
Lt. Dr. Chithra P. S. \\ Assistant Professor \\ Research \& Post Graduate Department of English \\ Sree Kerala Varma College \\ Kanattukara P. O.Thrissur - 680011 \\ Kerala, Email: skvccps@gmail.com
}

\begin{abstract}
This research article focuses on two innovative Malayalam films, Mela (1980), and Lekhayude Maranam Oru Flashback (1983) directed by K. G. George. These films showcase the life of the protagonists in the respective cities which they had reached with the hope of beginning a new chapter in their lives. In Mela, the hero Govindan who is portrayed as a dwarf succumbs to the perceptive discrimination of the co-artistes in his circus troupe. This film answers the question of how a marginalized man in an urban agglomeration, predominantly heteronormative, tries to establish his corporeality and the consequences thereof. Lekhayude Maranam Oru Flashback is a fine film which tries to expose the distressing realities of life inextricably intertwined in filming hubs like Kodambakkam, the soul of Chennai's film industry.
\end{abstract}

Keywords: Family, City, Cinema, Gender

Journeys, both temporally and spatially, have been a common theme in literature from time immemorial and they have often been used to delineate the transformation of the protagonist from the state of innocence to that of maturity.

In western culture, homo sapiens is not only understood as homo faber who makes tools and builds machines and thus enlarges his means of changing his surroundings, and as homo ludens who engages in aimless play and thus heightens his creativity, but also as homo viator who travels and thus broadens his horizon by experiencing the unknown. This is why the journey as a process of learning through travelling is an elementary manifestation of human life, and many languages bear witness to its role as a fundamental activity. (Freese 247)

The journey(s) undertaken by the protagonist can be inner journeys, physical journeys and/or imaginative journeys or can be multi-dimensional comprising of a 
Impact Factor: 4.845(SJIF) Research Journal Of English (RJOE) Vol-5, Issue-2, 2020

www.rioe.org.in An International Peer-Reviewed English Journal

ISSN: 2456-2696

Indexed in: International Citation Indexing (ICI), International Scientific Indexing (ISI), Directory of Research Journal Indexing (DRJI) Google Scholar \& Cosmos.

combination of these. Whereas on one hand, inner journeys mainly pave the way for the discovery of the self, on the other, in physical journeys the hero physically moves from one place to another and en route faces the possibility of encountering challenges and difficulties which need to be overcome. Not only this, the possibility of the geographical change affecting the life of the protagonist leading to his good or otherwise is a matter of consideration. Imaginative journeys are, de facto, journeys which deal with the imagination of the readers or viewers and how they are transported into an imaginary world. Irrespective of the type of journey, the functions of a journey are manifold and as Biggs succinctly opines, "By its very nature, the journey raises questions of agency and leadership, informing the relationship between the individual and community, male and female, parent and child, but also destabilizing these most rudimentary binaries: the journey links while it creates distance - it always functions in multiple dimensions" (2).

Given the fact that a journey can be considered to be a goal oriented enterprise, the scope of approaching it and interrogating it exists at various levels. Literature is abundant with works having different types of journeys as themes and the most notable among these would be, undoubtedly those which have the epic journey as their fulcrum since they provide, "a powerful framework for talking about "home" and its antitheses" (Biggs 2) and "perhaps unsurprisingly emerges as intrinsic to questions of identity both collective and individual; to the development of narratives; to historical employment; and to constructions of heroism" (2).

One aspect of this article is the description of the journey undertaken by the protagonist transporting him from one place to another one having an entirely different social, political, and cultural space that indeed affects the entire self and subjectivity of the character. A physical journey should not be treated as an end in itself and in fact leads to a kind of self realization which may result in an identity crisis. The most common physical journey depicted in literature is one that is undertaken by the protagonist from the village to the city which in turn leads to the creation of a new self as a consequence of the life's experiences during and after the journey. Freeze in his article, "The "Journey of Life" in American Fiction" opines that:

If one understands a journey as a movement from point $\mathrm{A}$ to point $\mathrm{B}$, the motive for such a movement can be that a traveler wants to get away from $\mathrm{A}$, that he wants to get to $\mathrm{B}$, or that he travels for the sake of travelling. Consequently in a taxonomic understanding, there are three basic journey types: (1) the journey as an escape from a given place with casual motivation (2) the journey as a search for a particular place or object with final motivation, and (3) the aimless movement between two places with inherent motivation. In concrete fiction, however, the need to escape from an old life might lead to a search for a new one, a failed search can end in an attempt to escape, a journey that spatializes an inner development might unfold as a teleological 
Impact Factor: 4.845(SJIF) Research Journal Of English (RJOE) Vol-5, Issue-2, 2020

www.rioe.org.in An International Peer-Reviewed English Journal

ISSN: 2456-2696

Indexed in: International Citation Indexing (ICI), International Scientific Indexing (ISI), Directory of Research Journal Indexing (DRJI) Google Scholar \& Cosmos.

journey that gradually moves towards a harmonious ending or culminates in a sudden life changing insight, or it might consists of aimless drifting that is an end in itself. Thus the basic types often exist simultaneously and in various combinations. (248)

The journey to a city or metropolis is often undertaken by the protagonist with a ray of hope for a new beginning of life, novel experiences and a novae exposure. Post this journey, an introspection needs to be done to ascertain whether the journey as a process of construction has yielded definitive results and whether it has been a constructive one or not. Another reason why a physical journey may be undertaken is to unravel the hitherto unknown realms of geographical areas which are the themes in road movies. However, this article limits its scope in studying the former aspect.

Space, whether urban or rural, is primarily a product of the totality of experiences by its inhabitants. The analysis of city in cinema has become one of the locus areas of critical inquiry. The city, as one finds it in history, is the point of maximum concentration for the power and culture of a community. systems of order. Here is where the issues of civilization are focused.... (Mumford 3)

Cinema being the most popular and recent cultural artifact has a great impact on the masses as a form of art for entertainment and for the representation of various elements that constitute the society. Among the different angles from which cinema can be critiqued, the study of the relationship between cinema and the city is quite interesting and provides scope for critical inquiry. Generally, in cinema, cities are marked by shots depicting urban agglomerations and include the atmosphere of busy streets, bridges, epic skylines, railroads, bars, theatres, restaurants, malls, big shops, concrete houses and the like. It has been noted that the cinema has grown with the city, or rather the growth of the city and cinema have been simultaneous in the initial stages of the development of cinema. American films contributing to the growth of American cities is an insightful example portraying the relationship between the two. Films like Taxi Driver (1976) and Manhattan (1979) have been set in New York City and it is quite interesting to see how these two films portray the same city differently. In Europe of the 1920s, Berlin was the locus of interest to depict the urban space as far as moviemakers were concerned. In Indian cinema, especially in Bollywood, initially, Mumbai, the megalopolis, had become the core of the plot in several films and subsequently, cities like Delhi have been featured. In Malayalam films also, big Indian and foreign cities have been depicted.

The principal themes and major foci of this article is the portrayal of the protagonists' journey from home to the city, depiction of the urban space in cinema, how this transition has a bearing on the life of the protagonists, how the concept of family is 
Impact Factor: 4.845(SJIF) Research Journal Of English (RJOE) Vol-5, Issue-2, 2020

www.rjoe.org.in An International Peer-Reviewed English Journal

ISSN: 2456-2696

Indexed in: International Citation Indexing (ICI), International Scientific Indexing (ISI), Directory of Research Journal Indexing (DRJI) Google Scholar \& Cosmos.

being perceived in the city and how the interplay of social power creates a cultural transformation in cities, with reference to the two Malayalam films Mela (1980), and Lekhayude Maranam Oru Flashback (1983). "The cities are both places of opportunity and obstacles that complicate stability" (Kaapa 68). This article also tries to probe deep into how the protagonists discover opportunities, and the ways and means they use to deal with encountered obstacles as well as the variegated challenges associated with urban life.

The migration of manpower to the gulf countries and the subsequent inflow of gulf money into Kerala had, in fact, a direct bearing on the psyche, attitude and life style of the people in the state. The decades of the 1970s and the 1980s can be referred to as a transitional period in the history of the state and the Malayalam cinema of this period also aptly and ingeniously highlights the changes including those associated with life style in the city and the village. Correspondingly, the two Malayalam films have been carefully so chosen as to coincide with this period in order to effectively bring out the fluidity associated with this transition to the forefront.

Broadly, Malayalam cinema can be divided into three groups, art cinema, middle cinema and commercial cinema. The selection and presentation of the themes as well as the use of techniques to present them are unique in each of these categories which in turn have been instrumental in the phenomenal growth of the Malayalam film industry as a whole. Art films are generally serious in nature focusing more on reality, whereas mainstream cinema which is also known as commercial cinema or popular cinema are focused on assuaging the masses with scenes of music, dance, comedy, and romance interspersed for attraction and entertainment. On the other hand, middle cinema, also termed as madhyavarthi cinema in the Malayalam language, is that genre which incorporates the elements of both art and commercial cinema. "The genre of movies called madhyavarthi cinema was ubiquitously staged as a genre of quality, in-between films which defied some of the cinematic conventions of both Malayalam kachavada (commercial) and kala (art) cinemas and self-consciously indulged in new film practices, carefully developed through principles of adaptation and refusal (Menon 105).

The Malayalam films Mela, and Lekhayude Maranam Oru Flashback which are being analysed in this present research paper, have been taken from the oeuvre of the renowned film director K. G. George, who also happens to be one of the pioneers of Malayalam middle cinema.

Amongst extant historiographies of regional cinemas of India, the Malayalam context currently constitutes one of the most consolidated of histories, its trajectory tracing divisions into epochs with clearly delineated borders. The broader categories of kala (art) cinema, kachavada (commercial) cinema and 
Impact Factor: 4.845(SJIF) Research Journal Of English (RJOE) Vol-5, Issue-2, 2020

www.rjoe.org.in An International Peer-Reviewed English Journal

ISSN: 2456-2696

Indexed in: International Citation Indexing (ICI), International Scientific Indexing (ISI), Directory of Research Journal Indexing (DRJI) Google Scholar \& Cosmos.

madhyavarthi (middle) cinema conveniently correspond to significant political economies in the broader history of the place. The canonization of particular films as benchmarks in Malayalam film history serves as the inevitable byproduct of such master narratives about Malayalam cinema history. Similar trends are discernable in other cinema histories: in the French context, the stylistic divisions into poetic realism, cinema du quality, new wave, historical retrospectives, and the cinema $d u$ look, seem similarly over-determined through the master narratives of political history. Yet scholars are now beginning to break from ossified trends and to explore neglected eras and previously discounted film works. In this new scene of recovering histories, K.G. George emerges as an interesting auteur. (Menon 105)

Among the many Malayalam films, Mela and Lekhayude Maranam Oru Flashback are two unique films in the sense that they deal with themes which are uncommon and deviant from the normal stereotypical narratives and precisely this fact opens up a plethora of opportunities for the researchers and film critics to read these films from several perspectives. The scope of this article limits itself to the analysis from the point of view of a journey undertaken to the city. Specifically it examines the different kinds of troubles and problems encountered by the protagonists in the urban space, the manner in which they negotiate with those hostile situations, the means employed to deal with these challenges and finally the indelible impact which these experiences have on themselves and their families. In the former film, the journey is undertaken by the male protagonist, who is a dwarf, along with his spouse, whereas in the latter, a woman with both her parents undertakes the journey to the alluring city with the hope for a bright future.

The primary sources selected for this study are the two Malayalam films Mela and Lekhayude Maranam Oru Flashback directed by K. G. George, the famous Malayalam film director of the 1980s. He graduated from the Film and Television Institute of India, Pune and was instrumental in experimenting with new themes for Malayalam films. The article employs a multidisciplinary approach where theoretical aspects from different branches of knowledge including History and Economics are being taken and discourse analysis is being done.

Mela is a unique film by George in which he casts a dwarf Govindan (Raghu) who is a joker in a circus troupe, as the hero. George in his autobiography opines that, "through the dwarf protagonist Raghu, the so far accepted heroic notions have been deconstructed and rewritten. Mela could portray the life and love of such people, who have been marginalized by the society in a different manner" (George 59).

The first half of the movie Mela, is the story of Govindan's journey from the city to the village. The dwarf Govindan marrying a normal beautiful woman, taking her to the city 
Impact Factor: 4.845(SJIF) Research Journal Of English (RJOE) Vol-5, Issue-2, 2020

www.rioe.org.in An International Peer-Reviewed English Journal

ISSN: 2456-2696

Indexed in: International Citation Indexing (ICI), International Scientific Indexing (ISI), Directory of Research Journal Indexing (DRJI) Google Scholar \& Cosmos.

with the hope of leading a normal married life, the situation turning problematic belying his hopes, the ways and means adopted by him to negotiate the unexpected turn of events, and the associated progressively increasing levels of depression culminating in his suicide form the narrative of the second half.

George, with his ingenuity, projects the main issue of the film to be the treatment which a person having deviation from heteronormal masculinity receives from the urban space when trying to assert his normal masculine traits and trying to lead a normal family life in the city. He achieves this objective by contrasting the treatment the person receives in the village with the starkly contrasting treatment which the same person gets in the city and by employing this technique, he very skillfully depicts that masculinity is not always a dominant ideology especially when there is a deviation, as in the case of Govindan.

George uses a long shot at the beginning of the film to depict the arrival of Govindan. The shot captures the typical scenic beauty of an Indian village with paddy fields in the background, and amidst this backdrop, Govindan dressed in his modern attire, comprising of trousers and a coat, and donning a pair of sunglasses is seen chugging along with a radio (considered to be a modern gadget of that time in a village) in his hand. The quintessential villagers, loving, caring and innocent, treat Govindan very affectionately and become enamored by his wealth and possessions. Govindan returns to his native village a perfect gentleman with an anglicized name, G. Vinde, and he gives an opportunity to the villagers to get a glimpse of some of the possessions which he had acquired in the course of his life in the city. The villagers become fascinated by seeing these and within a short span of time, the repute and respect of the villagers towards Govindan grow by leaps and bounds. G. Vinde's apparent good job in the city with a decent earning overshadows Govindan's stature and soon he turns out to be an eligible bachelor in the village with the parents of young women hoping that Govindan will become their son-in-law. In spite of Govindan's mother, Nani Amma, mooting the idea of his marriage several times, Govindan stalls the proposal each time because he feels that his physical structure will act as a serious impediment. In order to allay the apprehensions of her son, Nani Amma, cites an example:

NANI AMMA. Do you know how old you are?

GOVINDAN. I forgot that.

NANI AMMA. You have crossed twenty seven.

GOVINDAN. I thought I would have crossed forty.

NANI AMMA. You consider whatever I tell as a joke. Please listen to what

I say. There should be someone to cook and wash for you.

GOVINDAN. You are here for that. Right? And when you are not there, I will do it by myself.

NANI AMMA. Son, do you understand what I said? 
Impact Factor: 4.845(SJIF) Research Journal Of English (RJOE) Vol-5, Issue-2, 2020

www.rjoe.org.in An International Peer-Reviewed English Journal

ISSN: 2456-2696

Indexed in: International Citation Indexing (ICI), International Scientific Indexing (ISI), Directory of Research Journal Indexing (DRJI) Google Scholar \& Cosmos.

GOVINDAN. Yes, I understood.

NANI AMMA. Then stop joking and tell me (consent for marriage).

GOVINDAN. Will any girl like to marry me?

NANI AMMA. Why not? Don't any short men get married? Do you know the well known goldsmith in Vadakkemuri? He is shorter than you.

His wife is taller than him and they have four or five well built and normal children... will be many girls ready to marry you. (Mela)

George presents a new turn of events in the married life of Govindan and Sarada when the former takes his wife to the city where their life unfortunately heads in the direction which is most unexpected. He also very skillfully presents the various challenges which they encounter in the city, hitherto never experienced by them in the village, and their decisive influence on their personal lives. The incidents like, when he is attacked by a group of men while walking through the streets in the city with his wife, who mock at him when he says that Sarada is his wife; how people including Sarada and Vijayan burst into laughter when he collides with a waiter in the hotel and falls down; and comments from his boss saying that marriage is not meant for people like Govindan, question his very existence as a man. His not being in accordance with the norms of heteronormativity, due to his short stature culminates in his experiencing a kind of identity crisis. Govindan's very identity as a man is being questioned by the city folk and this results in an ambiguity in his mind causing a dilemma that he had never experienced in his village life. Taking into account that populace in urban spaces is prone to facing several such social problems, George has very subtly fused this fact in this film.

The diminution of status from that of being a hero to that of being a socially awkward person within a short span of time, further compounded by the fact that his wife is witness to the sequence of events, takes a heavy toll on Govindan and makes him reach a point of being an emotional wreck. The drastic fall can be attributed to the sinister intentions of his colleagues in the circus troupe, where he is working as a clown. Skilfully they carve out a malicious interpretation of his wife's relationship with another man, Vijayan (Mammootty) in the circus troupe and one gets to see these sort of actions more in the urban space which brings to the forefront the hidden evilness lurking deep and waiting to pounce upon the gullible.

The happiness in the first half of the film gradually gives way to sadness in the second half. Govindan and Sarada reach the city with the hope of starting a happy married life, but what awaits them is something quite contrary to their hopes and expectations. The turn of events and the resultant outcomes, make him feel that he is a social and psychological misfit who is unfit to live in this world and concludes that people like him will never receive any acceptance from the society at large which will in turn pose to be a 
Impact Factor: 4.845(SJIF) Research Journal Of English (RJOE) Vol-5, Issue-2, 2020

www.rioe.org.in An International Peer-Reviewed English Journal

ISSN: 2456-2696

Indexed in: International Citation Indexing (ICI), International Scientific Indexing (ISI), Directory of Research Journal Indexing (DRJI) Google Scholar \& Cosmos.

big hindrance to leading a normal life with a beautiful wife and children. His outlook towards life becomes marred by negativity and finally, utter dejection drives Govindan to commit suicide. The city and its people make it exceedingly difficult for him to lead a happy life. Had he continued to live in his native village, undoubtedly, he would have survived and would have led a happy family life.

Elizabeth Wilson, in her book, The Sphinx in the City opines that a city is a place of liberation as well as of danger for women where the theme of prostitute and prostitution recur in urban life (8). Lekhayude Maranam Oru Flashback is about a woman aspiring to become a film actress. She leaves her village and goes to Madras (now Chennai), where she encounters an unexpected turn of events. Lekha (Nalini), the heroine, reaches the city with hopes and expectations of becoming an actress in the film industry. This film, which the viewers get to see in flashback mode, can be broadly divided into four sections, all of which describe the ups and downs in Lekha's life and career.

The time span ranging from July to October 1977 depicts the transformation of Lekha from a village girl to a prostitute operating in the streets of Kodambakkam, Chennai. Lekha's mother, Vishalakshy (Subha) is eager to make her daughter a film actress and in pursuit of this aspiration of hers, decides to leave her native village in Kerala and proceed to Chennai along with Lekha, whose real name is Santamma. It does not take long for the vicious nature of the city life to catch them in its vice like grip and make them plunge headlong into quicksand. Lekha and her mother start visiting various filmmakers and soon they become aware of the prevalent ill practices existing in the industry. Initially, Lekha's mother does not succumb to the demands of the filmmakers, but soon the pomp and quick money dangling like a carrot in front of her eyes get the better of her and hesitation gives way to acceptance, following which she slowly persuades Lekha to take up prostitution as a means of living.

In a short time, Lekha loses her virginity in the hands of Paul (Nedumudi Venu), an upcoming director, who entices Lekha by saying that she is going to be the heroine in his next film. Giving credence to his words, Lekha and her family come to live in a street in Kodambakkam, the go-to address for all those wishing to be associated with the film industry, and just like many of the other women staying here, cherishing the desire of becoming an actress someday, Lekha starts earning money through prostitution for a living.

The next section in the film picturises the golden period of Lekha's life; she becomes a leading actress and wins a National award for being the best actress. She now starts earning a good and steady income. Her new house is full of luxuries and modern amenities of the time and includes a television, telephone and a four wheeler. Her step by step growth and the resultant money power make her more independent which eventually 
Impact Factor: 4.845(SJIF) Research Journal Of English (RJOE) Vol-5, Issue-2, 2020

www.rioe.org.in An International Peer-Reviewed English Journal

ISSN: 2456-2696

Indexed in: International Citation Indexing (ICI), International Scientific Indexing (ISI), Directory of Research Journal Indexing (DRJI) Google Scholar \& Cosmos.

leads to her asserting freedom in decision making. She gradually falls in love with Suresh Babu (Bharat Gopi), the famous director. Suresh Babu is a married man with a child and Lekha, in spite of knowing the fact that marriage is a sacrosanct union and that it is not customary to begin a relationship with deceit, foregoes all traditional values and continues this association; George's classic depiction of the vices of a city coming into play.

By this time, Lekha realises that she had turned into a mere instrument for making money in the eyes of her family and everybody including her mother are not paying any heed towards the fact that it is high time she gets married and settles down in life. Her parents try to discourage her from indulging in a relationship with Suresh Babu, but paying scant attention to her parents' words and disobeying them, she asserts her freedom by deserting them and proceeds to live with him. "The city is the zone of individual freedom. There, the ties of family and kinship may be loosened and avenues of escape may open up" (Wilson 16).

Lekha's elopement with Suresh Babu sends shock waves in her family and causes turbulence in the family of Suresh Babu as well. His wife Geetha (Sarada) and child coming and meeting Lekha and bringing him back into Geetha's fold brings about a bad turn in Lekha's destiny. This visit clearly depicts the attitude of Suresh Babu towards Lekha and how important his original family is for him.

SURESH BABU. I thought you might have gone for the shooting. Why did you not go? Some of my files are here. (Lekha is sobbing. Suresh Babu comes near her bed and sits on a chair). You are a fool. I have to go with my wife and child when they come and call me. Right? Don't worry. I will come as and when I get time. You need not disclose this to anybody.

LEKHA. Only as per your convenience?

SURESH BABU. I have already told you that this is only an adjustment. It is your fault that you have taken it (this relationship) seriously.

LEKHA. Were you not serious?

SURESH BABU. See, I love you. But I cannot marry you leaving my wife. Marriage is a serious issue.

LEKHA. Then, I am no one to you. Right?

SURESH BABU. You...

LEKHA. Mistress. Right?

SURESH BABU. You call it whatever name you want. It is not possible for me to explain everything to you. You will not understand it. I will come on Sunday.

LEKHA. For what?

SURESH BABU. Should I not come? Then no need. I have not forced anyone to do anything. You did everything according to your wish. If you 
Impact Factor: 4.845(SJIF) Research Journal Of English (RJOE) Vol-5, Issue-2, 2020

www.rjoe.org.in An International Peer-Reviewed English Journal

ISSN: 2456-2696

Indexed in: International Citation Indexing (ICI), International Scientific Indexing (ISI), Directory of Research Journal Indexing (DRJI) Google Scholar \& Cosmos.

are feeling distressed now, you may go back home. According to me, I will consider this as an aborted adventure. Lekha, I don't have the time to be here. You think and take a decision. We will meet again. (Lekhayude Maranam Oru Flashback) The above dialogue between Lekha and Suresh Babu, in fact, shatters Lekha.

Coming to a metropolis with hope and aspirations, she ends up becoming a prostitute and then for some time, fortune smiles on her and she succeeds in her career as a film artiste. But the real life, in contrast to the reel life, does not behave considerately to Lekha and the attempt she makes to lead a happy life, according to her likes, fails miserably leading her to commit suicide out of sheer despondency. "Important for film as a new medium associated with modernity was also the filmic construction of those unable to negotiate the city with its pitfalls and its pleasures... . These narrative constructions of a rural character coming to the city unable to negotiate its dangers and seductions, often embodied by a female character, continue throughout the history of film" (Mennel 9).

Mela focuses on the life of a dwarf man in the city when his heteronormative masculinity is being questioned and the manner in which he has been denied a happy married life with a beautiful woman. The majority of the people in the city, both men and women alike, consider the protagonist, Govindan to be just a clown with no inherent masculine qualities and they marginalise people like him. In Lekhayude Maranam Oru Flashback one gets to see the commoditization of relationships in the city and how this drags the heroine to the immoral and demeaning profession of prostitution as well as how she has been portrayed as an object of pleasure by the male characters leading to the woman's total destruction.

This article has attempted to read the urban space as a socially constructed space where meanings, symbols and signs play with each other to interpret the ways of life, the relationship among people as well as what a city space provides for a human being and whether it influences his or her life in a positive manner or a negative one. Further scope for study exists in both these films. In Mela, the role of a man's body can be deliberated upon. Lekhayude Maranam Oru Flashback can be critiqued from a feminist point of view in terms of women making their appearance in the public sphere.

References:

- Biggs, Thomas and Jessica Blum. The Epic Journey in Greek and Roman Literature.Cambridge UP., 2019.

- Freese, Peter. "Journey of Life in American Fiction". Hungarian Journal of English and American Studies, vol. 19, no. 2, 2013, pp. 247-283. JSTOR, www.jstor.org/stable/44789678. 
Impact Factor: 4.845(SJIF) Research Journal Of English (RJOE) Vol-5, Issue-2, 2020

www.rioe.org.in An International Peer-Reviewed English Journal

ISSN: 2456-2696

Indexed in: International Citation Indexing (ICI), International Scientific Indexing (ISI), Directory of Research Journal Indexing (DRJI) Google Scholar \& Cosmos.

- George, K. G. Flashback: Enteyum Cinemayudeyum. D. C., 2012.

- ---, director. Lekhayude Maranam Oru Flashback. Sathru International, 1983.

- ---, director. Mela. Visal Movies, 1980.

- Kääpä, Pietari. "Mapping Transnational Space at the Margins of the Global Metropolis:

- Representations of the City in Kaurismäki's Films". The Cinema of Mika Kaurismäki. Intellect, 2011. JSTOR, www.jstor.org/stable/j.ctv9hj8rv.7.

- Mennel, Barbara. Cities and Cinema. Routledge, 2008.

- Menon, Bindu. "Malayalam Middle Cinema and the Category of Woman". Women in Malayalam Cinema: Naturalizing Gender Hierarchies, edited by Meena T. Pillai, Orient, 2010, pp. 105-121.

- Mumford, Lewis. The Culture of Cities. Harcourt, Brace, 1938.

- Wilson, Elizabeth. The Sphinx in the City: Urban Life, the Control of Disorder, and Women.Virago,1991. 